\title{
SUPRACONDYLAR FRACTURE; \\ COMPARISON OF OUTCOMES OF OPEN VERSUS CLOSED PERCUTANEOUS K-WARE FIXATION IN DISPLACED SUPRACONDYLAR FRACTURE.
}

1. MBBS
House Officer
Jinnah Hospital, Lahore
2. MBBS
House Officer
Jinnah Hospital Lahore
3. MBBS
House Officer
Jinnah Hospital Lahore,
4. MBBS, FCPS
Assistant Professor
College of Dentistry
Nishtar Medical University Multan.

Correspondence Address:

Dr. Aamir Furqan

Assistant Professor

College of Dentistry

Nishtar Medical University Multan

draamir2009@hotmail.com

Article received on:

30/03/2017

Accepted for publication:

26/06/2017

Received after proof reading:

03/07/2017

\section{Awais Talib', Ch. Muhammad Atif Niaz², Yasir Sultan ${ }^{3}$, Aamir Furqan ${ }^{4}$}

ABSTRACT... Objectives: is to compare the outcomes of open versus closed Percutaneous $\mathrm{K}$ wire fixation in displaced supracondy fracture of humerus in children. Period: May 2016 to May 2017. Setting: Orthopedic unit of Nishtar Hospital Multan. Methodology: Total number of $170(100 \%)$ patients of displaced supracondylar fracture of humerus was enrolled. Patients were divided into two equal groups by lottry method ( 85 patients in each group). SPSS version 23 was used to analyze the data, mean and standard deviation was calculated for numerical variables like age and flayn et al score, and frequencies with percentages were calculated for categorical variables like gender and outcome variable satisfactory/unsatisfactory. Chi square test was applied to see the effect of effect modifiers on outcome variable. $P$ value of $\leq 0.05$ was considered as significant. Results: Total of $170(100 \%)$ divided in two equal groups $A$ and B, 85 patients in each group. Out of 170 patients $97(57.1 \%)$ were male and $73(42.9 \%)$ were female. Out of these in group A $75(88.1 \%)$ patients have satisfactory outcome and 10 (11.7\%) patients have unsatisfactory outcome. Similarly in group B, 71 (83.5\%) were having satisfactory and $14(16.47 \%)$ have unsatisfactory outcome and $P=0.37$. Conclusion: Results of our study concluded that open reduction with $\mathrm{K}$ wire fixation technique have better satisfactory outcome (union rate) as compared to closed reduction and $\mathrm{K}$ wire fixation in the management of supracondaylar fracture of humerus in young age group.

Key words: $\quad$ K wire, Supracondaylar fracture, Humerus, Open reduction.

Article Citation: Talib A, Niaz CMA, Sultan Y, Furqan A. Supracondylar Fracture: Comparison of outcomes of open versus closed percutaneous $\mathrm{k}$-ware fixation in displaced supracondylar fracture. Professional Med J 2017;24(7):997-1001.

DOI: $10.17957 / T P M J / 17.4091$

\section{INTRODUCTION}

Supracondylar fracture is the fracture of distal end of humerus just above the epicondyles. It's location at the transformation zone, where the shape of bone changes from tubular to flat, adds difficulty to achieve and maintain satisfactory reduction. Hippocrates narrated supracondylar fracture of humerus in his writings about 300 years BC. This common fracture accounts for $3 \%$ of all fractures ${ }^{1,2}$ and $60-80 \%$ of elbow fractures in children. ${ }^{3}$ On the basis of direction of displacement of distal fragment supracondylar fracture are classified in to posterior and anterior types. Posterior displacement constitutes 97\% of all supracondylar fractures occurring mainly due to fall on outstretched hand as compared to rare anterior displacement ( $3 \%$ of all cases) $)^{4,5}$ resulting from a direct violence with joint in flexion. Though the extension type of supracondylar fracture can be classified depending on based on type and location of fracture line and the degree of displacement of the fractured segment but the Gartland ${ }^{6}$ classification is generally followed. Gartland classified supra condylar fracture in to type I, II and III representing which are undisplaced, displaced with intact posterior cortex and completely displaced with no contact between the fragments respectively.

Surgical treatment improves outcome and lowers the incidence of neuro-vascular complications ${ }^{7}$ rendering it a safe procedure with a slightincreased risk of infection. A lot of surgical techniques are described in order to treat this fracture. Lee et $\mathrm{al}^{8}$ narrated the superiority of lateral pinning technique over medial and lateral crossed pinning technique for peadriatic Supracondylar fractures of the humerus. However, higher incidence 
of cubitus varus and ulnar nerve injury were reported in various studies, owing to incomplete visualization of the medial column comminution and tilt in lateral pinning technique. ${ }^{9}$ So, avoiding permanent ulnar nerve palsy might be more precious than a favorable outcome. Safety and effectiveness of closed reduction and crossed pinning of displaced Supracondylar fractures of humerus was advocated by Dua et al. ${ }^{10}$

An excellent healing with favorable outcome by using open treatment of distal humeral fractures with an extensor mechanism-on approach was observed by Erpelding et al. ${ }^{11}$ Woratanara et al. ${ }^{11}$ argued on the preference of lateral pinning to cross pinning for fixation of pediatric Supracondylar humerus fractures focusing on the risk of ulnar nerve injury. The comparison of stability and risk of ulner nerve injury on using properly placed lateral pin construct and medial and lateral pin fixation was done in a retrospective study. Closed reduction and percutaneous $\mathrm{K}$ wire fixation gave $100 \%$ excellent outcome compared to $93 \%$ good outcome following open reduction and internal fixation in a study conducted by Kaewpornsawan $\mathrm{K}$ et $\mathrm{al}^{12}$ using Flynn et $\mathrm{al}^{13}$ criteria. Our study was conducted to determine the best technique with least complications by comparing open reduction and close percutaneous k-wire fixation for managing supracondylar fracture of humerus in children.

\section{METHODOLOGY}

After the approval of ethical committee, 170 patients, with supracondylar fracture of humerus, were selected fulfilling the inclusion criteria from the orthopedic unit of Nishtar Hospital Multan. Sample size was calculated with $95 \% \mathrm{Cl}, 80 \%$ power of test and P1 percentage of group 1, $100 \%{ }^{13}$ and of group 2, 93\% with help of openepi. com. All the patients were divided into two groups by using lottery method after the written consent of their guardians. Group A patients were managed with closed reduction and K-wire fixation while those of group B were managed by open reduction and k-wire fixation. All patients were undergone surgery under general anesthesia by the same qualified surgeon having 5 years of experience assisted by researcher himself. Both anteroposterior and lateral view radiographs of elbow were reviewed and angles measured. Range of motion of elbow (flexion/extension) at presentation and final follow up were recorded. The patients were followed up to three months. Final outcome was measured at the end of 12th week postoperatively. All the information including outcome variable was recorded on a specially designed Performa. Stabilization of fracture site with the use of hardware (K-Wire) was termed as fixation. Carrying angle is the angle between long axis of humerus and long axis of ulna with normal value of 8-11 degrees. Any deviation from 8-11 degree was regarded as loss of carrying angle (measured on an AP radiograph). Functional factor was measured in terms of range of flexion and extension at elbow. An extension of 0 degree and a flexion of 120 degree were considered normal and any deviation from these degrees was measured.

Outcome was determined by Flyn et al criteria at 10 weeks. A collective score of $\leq 30$ was considered satisfactory and $>30$ unsatisfactory. Patients with Gartland's type 1 fracture, maltreated fractures, Age $<5$ years and $>12$ years were excluded from our study. Data was analyzed using SPSS v 16.0. Mean and standard deviation were calculated for quantitative variables like age, duration of fracture. Categorical variables like gender were presented as frequency and percentage. Chi square test was applied to test hypothesis. Effect modifiers like age and gender were controlled by stratification. Post stratification chi square test was applied and a $P$ value of $<$ 0.05 was considered significant.

\section{RESULTS}

Total of 170 (100\%) divided in two equal groups $A$ and B, 85 patients in each group. Out of 170 patients $97(57.1 \%)$ were male and 73 (42.9\%) were female. In group $A$ there were 43 male and 41 female patients and in group B, 54 male and 31 female Table-I. As concern to the type of fracture 91 (53.5\%) patients have Gartland type II fracture and 79 (46.5\%) patients have Gartland type III fracture. On stratification it is found that 
in group A, 48 patients have Gartland type II fracture and 37 patients have Gartland type III fracture, similarly in group B, 43 patients were having Gartland type II fracture and 42 patients have Gartland type III fracture (Table-II). When we concern about outcome variable 146 (85.9\%) patients were having satisfactory outcome and $24(14.1 \%)$ were having unsatisfactory outcome. Out of these in group A 75 (88.1\%) patients have satisfactory outcome and $10(11.7 \%)$ patients have unsatisfactory outcome. Similarly in group $\mathrm{B}, 71(83.5 \%)$ were having satisfactory and 14 (16.47\%) have unsatisfactory outcome and $P=$ 0.37 . When we concern about age of patients mean age and SD of patients in in group $A$ was $8.45 \pm 2.32$ and in group B, $8.55 \pm 3.32$ (TableII). When we calculate mean Flayn et al score and SD in group A was $1.94 \pm 1.06$ and in group $B$ $2.06 \pm 0.838$. Mean duration of fracture and SD in group $A$ was $1.96 \pm 0.82$ and in group $B, 1.85$ \pm 0.83 . Mean weight of patients and SD in group A was $22.2 \pm 4.66$ and in group $B, 21.95 \pm 5.01$.

\begin{tabular}{|c|c|c|}
\hline Characteristics & $\begin{array}{l}\text { Group A } \\
(n=85)\end{array}$ & $\begin{array}{l}\text { Group B } \\
(n=85)\end{array}$ \\
\hline Mean Age & $8.45 \pm 2.32$ & $8.55 \pm 2.32$ \\
\hline Mean Flayn et al score & $1.94 \pm 1.062$ & $2.06 \pm 0.838$ \\
\hline Mean Duration of fracture & $1.96 \pm 0.823$ & $1.85 \pm 0.838$ \\
\hline Mean Weight & $22.42 \pm 4.66$ & $21.95 \pm 5.01$ \\
\hline \multicolumn{3}{|l|}{ Gender Distribution } \\
\hline Male & $43(36.5 \%)$ & $42(35.7 \%)$ \\
\hline Female & $54(45.9 \%)$ & $31(26.3 \%)$ \\
\hline \multicolumn{3}{|c|}{$\begin{array}{l}\text { Table-I. Demographic Variable and Mean Flayn et al } \\
\text { score }\end{array}$} \\
\hline Chractaristics & $\begin{array}{l}\text { Group A } \\
(\mathrm{n}=\mathbf{8 5})\end{array}$ & $\begin{array}{l}\text { Group B } \\
(\mathrm{n}=85)\end{array}$ \\
\hline \multicolumn{3}{|l|}{ Type of Fracture } \\
\hline Gartland II & $48(40.8 \%)$ & $37(31.4 \%)$ \\
\hline Gartland III & 37 (31.4\%) & $42(35.7 \%)$ \\
\hline \multicolumn{3}{|l|}{ Outcome } \\
\hline Satisfactory & 75 (63.7\%) & 10 (8.5\%) \\
\hline Unsatisfactory & $71(60.35 \%)$ & $14(11.9 \%)$ \\
\hline P Value & \multicolumn{2}{|c|}{0.37} \\
\hline \multicolumn{3}{|c|}{$\begin{array}{l}\text { Table-II. Satisfactory outcome and percentage of } \\
\text { Gartland Fracture }\end{array}$} \\
\hline
\end{tabular}

\begin{tabular}{|l|c|c|c|}
\hline \multicolumn{1}{|c|}{$\begin{array}{c}\text { Age } \\
\text { groups }\end{array}$} & Satisfactory & Unsatisfactory & P Value \\
\hline $5-8$ years & 73 & 12 & 0.000 \\
\hline $9-12$ years & 73 & 12 & \\
\hline Total & 146 & 24 & \\
\hline Table-III. Association of Age groups with outcome \\
variable
\end{tabular}

\section{DISCUSSION}

Gartland type III fracture is a challenge for orthopedic surgeons as no single study recommended its definite treatment modality as a choice of management for this type of fracture type. There is little consuses on its reduction and Fixation methods ${ }^{14}$, but with these techniques there is $4-15 \%$ chances of ulnar nerve damage were documented. Sometime location of ulnar nerve on palpation may mis leads the surgeon and insertion of pin at medial location may injured the ulnar nerve supply. ${ }^{15}$ It is more difficult to point out the landmarks of bone when swelling is there and complications like cubits varus, distance tilt of fragment andeemanipulaton may increase when surgery was performed in such conditions. ${ }^{16}$ Radiological assessment of of Bauman's angle and final carrying angle is also a challenge in this swollen condition. ${ }^{17}$

Closed reduction of already manipulated cases or managed with bonesetters is quit difficult, so this kind of cases must be managed with open reduction method. Treatment of such major fractures with open reduction and internal fixation technique is widely accepted with all complications. Complications of infections can be compensated with good outcomes and less incidence of vascular damage. It is recommended safe procedure with good results.

Open reduction can be performed with different approaches like medial approach, lateral approach and posterior approach. These three approaches have their own complication types and incidence rate, cubitus varus is common in all.

In a study wailand found a higher rate of cubitus varus in lateral approach as compare to medial 
and posterior. ${ }^{17}$ Same rate was also reported by the surgeons in posterior approaches, so these two techniques of lateral and posterior approaches are less likely to gain surgeons satisfaction during or after surgical outcomes. ${ }^{18}$ But medial approach have minimum complications because it passes through the natural route (plane between brachialis and triceps) no new tissues and muscles involve in this technique. ${ }^{19}$

In a study Sibly et $\mathrm{al}^{20}$ tested the patients with posterior approach in all cases (35) and pinned them all and extension loss was reported. Similarly Gubber and Hodson ${ }^{21}$ also found same results with posterior technique. He found ulnar nerve damage in $25 \%$ of cases. In our study $85.2 \%$ patients satisfactory results. Our results are comparable with findings of Ramji Lal Sahu et $\mathrm{al}^{22}$ study who reported $88.3 \%$ excellent results mean satisfactory outcomes. Most of the studies on this topic have finding near about our findings.

But in a study Khan MS et $\mathrm{al}^{23}$ reported only $65 \%$ union rate (excellent results) and $20 \%$ patients were found good outcome. While in another study $88 \%$ stability was reported by Antoine et al.(24) Our results also comparable with results of Kow $\mathrm{RY}$ et $\mathrm{al}^{25}$ study who reported $85.5 \%$ satisfactory outcomes (excellent score of Flyn et al criteria).

\section{CONCLUSION}

Results of our study concluded that open reduction with $\mathrm{K}$ wire fixation technique have better satisfactory outcome (union rate) as compared to closed reduction and $\mathrm{K}$ wire fixation in the management of supracondaylar fracture of humerus in young age group.

Copyright@ 26 Jun, 2017.

\section{REFERENCE}

1. Li J, Fu D, Yu C, Wang S, Ze R, Tang X. Surgical management of delayed irreducible Gartland III supracondylar fractures in children: open reduction and internal fixation versus external fixation. Journal of shoulder and elbow surgery. 2017; 26(2):299-304.

2. Reisoglu A, Kazimoglu C, Hanay E, Agus H. Is pin configuration the only factor causing loss of reduction in the management of pediatric type III supracondylar fractures? Acta orthopaedica et traumatologica turcica. 2017; 51(1):34-8.

3. Iwegbu G. Principles and management of acute orthopaedic trauma: AuthorHouse; 2015.

4. Nduaguba A, Flynn J. Supracondylar Humerus Fracture. The Pediatric Upper Extremity. 2015:1121-36.

5. Carson S, Woolridge DP, Colletti J, Kilgore K. Pediatric upper extremity injuries. Pediatric clinics of North America. 2006; 53(1):41-67.

6. Gartland JJ. Management of supracondylar fractures of the humerus in children. Surgery, gynecology \& obstetrics. 1959; 109(2):145.

7. Hussain S, Dhar S, Qayoom A. Open reduction and Internal Fixation of displaced Supracondylar Fractures of humerus with Crossed K-wires via Medial Approach. Malaysian orthopaedic journal. 2014; 8(2):29.

8. Lee KM, Chung CY, Gwon DK, Sung KH, Kim TW, Choi $\mathrm{IH}$, et al. Medial and lateral crossed pinning versus lateral pinning for supracondylar fractures of the humerus in children: decision analysis. Journal of Pediatric Orthopaedics. 2012; 32(2):131-8.

9. Eren A, Ozkut AT, Altintas F, Guven M. Comparison between the lateral and medial approaches in terms of functional and cosmetic results in the surgical treatment of type III supracondylar humeral fractures in children. Acta Orthop Traumatol Turc. 2005; 39(3):199-204.

10. Dua A, Eachempati KK, Malhotra R, Sharma L, Gidaganti $M$. Closed reduction and percutaneous pinning of displaced supracondylar fractures of humerus in children with delayed presentation. Chinese Journal of Traumatology (English Edition). 2011; 14(1):14-9.

11. Erpelding JM, Mormino MA, Fehringer EV. Distal Humeral Fracture Fixation with an Extensor Mechanism-on Approach. JBJS Essent Surg Tech. 2012; 2(2):e9.

12. Kaewpornsawan K. Comparison between closed reduction with percutaneous pinning and open reduction with pinning in children with closed totally displaced supracondylar humeral fractures: a randomized controlled trial. Journal of Pediatric Orthopaedics B. 2001; 10(2):131-7.

13. Flynn JC, Matthews JG, Benoit RL. Blind pinning of displaced supracondylar fractures of the humerus in children. J Bone Joint Surg Am. 1974; 56(2):263-72.

14. Edwardson S, Murray O, Joseph J, Duncan R. Paediatric supracondylar fractures: an overview of 
current management and guide to open approaches. Orthopaedics and Trauma. 2013; 27(5):303-11.

15. Browner BD. Skeletal trauma: basic science, management, and reconstruction: Elsevier Health Sciences; 2009.

16. Starkey C, Brown SD. Examination of orthopedic \& athletic injuries: FA Davis; 2015.

17. Ashhurst APC. An anatomical and surgical study of fractures of the lower end of the humerus: Lea \& Febiger; 1910.

18. Venkatadass K. Address of Correspondence. Consultant. 2015;1(1).

19. Sölveborn S-A. Emergency Orthopedics. 2014.

20. Sibly T, Briggs P, Gibson M. Supracondylar fractures of the humerus in childhood: range of movement following the posterior approach to open reduction. Injury. 1991; 22(6):456-8.
21. Gruber MA, Healy III WA. The posterior approach to the elbow revisited. Journal of Pediatric Orthopaedics. 1996; 16(2):215-9.

22. Sahu RL. Percutaneous K-wire fixation in paediatric Supracondylar fractures of humerus: A retrospective study. Nigerian Medical Journal. 2013; 54(5):329.

23. Khan MS, Sultan S, Ali MA, Khan A, Younis M. Comparison of percutaneous pinning with casting in supracondylar humeral fractures in children. $J$ Ayub Med Coll Abbottabad. 2005; 17(2):33-6.

24. De Gheldere A, Bellan D. Outcome of Gartland type II and type III supracondylar fractures treated by Blount's technique. Indian journal of orthopaedics. 2010; 44(1):89.

25. Kow R, Zamri A, Ruben J, Jamaluddin S, Mohd-Nazir M. Humeral Supracondylar Fractures in Children: A Novel Technique of Lateral External Fixation and Kirschner Wiring. Malaysian Orthopaedic Journal. 2016; 10(2):41.

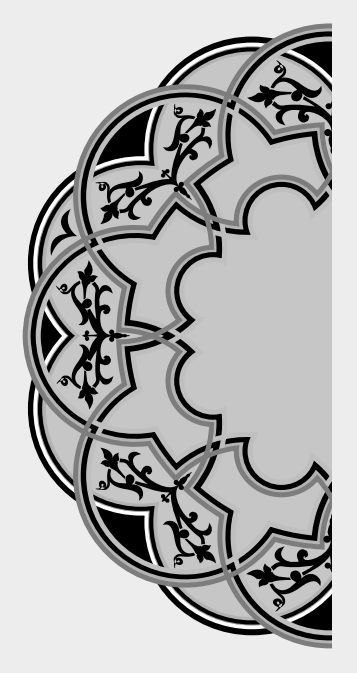

\title{
"Adversity makes strange bedfellows."
}

\author{
Unknown
}

\section{AUTHORSHIP AND CONTRIBUTION DECLARATION}

\begin{tabular}{|c|l|l|c|}
\hline Sr. \# & \multicolumn{1}{|c|}{ Author-s Full Name } & \multicolumn{1}{|c|}{ Contribution to the paper } & Author=s Signature \\
\hline 1 & Awais Talib & $\begin{array}{l}\text { Principal investigator, data } \\
\text { analysis, interpretation } \\
\text { Data collection, manuscript } \\
\text { writing, proof reading } \\
\text { Data analysis, Reference, }\end{array}$ \\
2 & Ch. Muhammad Atif Niaz & $\begin{array}{l}\text { Proof reading } \\
\text { Manuscript writing, } \\
\text { drafting, proof reading }\end{array}$ \\
\hline 3 & Yasir Sultan & Aamir Furqan &
\end{tabular}

